\title{
Diz artroplastisinin revizyon komplikasyonları
}

\author{
Complications of revison of total knee arthroplasty
}

\author{
Ahmet Murat Bülbül, Ahmet Güray Batmaz \\ İstanbul Medipol Üniversitesi Tıp Fakültesi, İstanbul
}

\begin{abstract}
Diz artroplastisi günümüzde sıkça kullanılan, hasta memnuniyeti yüksek tedavi yöntemlerinden birisidir. Bu tedavi yönteminin, ilerleyen zamanla, ortalama \%3-8 arasında değişen revizyon oranları bildirilmiştir. Revizyon cerrahisi tek veya çok aşamalı olarak gerçekleştirilebilmektedir. Ancak revizyon cerrahilerinin de bir takım komplikasyonları mevcuttur. Geniş kemik kayıpları, yumuşak doku problemleri, tekrarlayan enfeksiyonlar hatta mortalite bu komplikasyonların bazılarındandır. Bu yazının amacı, diz artroplasti revizyonlarının kısa bir özetini sunmaktır.
\end{abstract}

Anahtar sözcükler: diz artroplastisi, revizyon; komplikasyon
Total knee arthroplasty is a widely used treatment modality with high patient satisfaction. Over a time of period $3-8 \%$ of them goes to revision surgery. Revision surgery can be done in single- or multi-stage modes. However, revision surgeries also have complications. Some of these are massive bone defects, soft tissue coverage defects, reinfections or even mortalities. Aim of this manuscript is to give an overall brief summary of the complications of revision knee arthroplasties.

Key words: knee arthroplasty, revision; complication

yükseldiği bildirilmiştir. Bu artışının nedenleri arasın$\mathrm{da}$, genç yaşta yapılan protez cerrahi sayısının giderek artışı gösterilmiştir. Erkek ve 60 yaşından küçük hastalarda bu risk artarken, arka çapraz bağı kesen veya koruyan, patella değiştiren veya değiştirmeyen protezlerde belirgin farklılık bulunmamıştır. Tekrarlayan revizyonun en sık nedeninin, derin enfeksiyon ve instabilite olduğu bildirilmiştir. ${ }^{[3,4]}$ Bu yazıda amacımız, revizyon cerrahilerinde karşılaşılabilen komplikasyonların özetini sunmaktır.

\section{ENFEKSIYON}

Revizyon cerrahilerinin nedenleri arasında ilk sıralarda protez çevresi enfeksiyonları yer almaktadır. Enfeksiyon tanısını koymak her zaman kolay olmamaktadır. Parvizi ve ark. enfeksiyon tanısını koyabilmek için 6 parametre belirlemiştir. Bunlar; preoperative aspirasyon, sedimentasyon, CRP, serumda beyaz küre yüksekliği, kültür ve histolojik incelemedir. ${ }^{[5]}$ Bunlardan eklem aspirasyon sıvısının incelenmesi ve serum inflamasyon markerları tanı koymakta yeterli

Norveç'ten yapılan bir çalışmada, revizyon cerra-

- İletişim adresi: Doç. Dr. Ahmet Murat Bülbül, İstanbul Medipol Mega Hastaneler Kompleksi, TEM Avrupa Otoyolu Göztepe Çıkışı No: 1 Bağcılar, İstanbul Tel: 0542 - 2153173 e-posta: muratbulbul@yahoo.com

- Geliș tarihi: 8 Nisan 2015 Kabul tarihi: 8 Nisan 2015 
olabildiğini destekleyen yayınlar olduğu gibi, aseptik gevşeme olarak değerlendirilen revizyon cerahilerinin $\% 28$ 'inde aslında derin enfeksiyon olduğunu gösteren yazılar da mevcuttur. ${ }^{[6,7]}$ Artmış cerrahiler ile birlikte enfeksiyon oranları da giderek artmaktadır. ${ }^{[8]}$ Tedavide debridman ve polietilen değiştirilmesi, tek aşamalı revizyon, iki aşamalı revizyon, artrodez ve ampütasyona kadar gidebilen yöntemler mevcuttur. Bu tedavilerin içerisinde altın standart yöntem iki aşamaIı revizyondur. Iki aşamalı revizyon ile başarı oranları \%80-100 arasında bildirilmiştir. ${ }^{[9]}$ Ancak reenfeksiyon oranları da \%40'lara kadar seyrettiğine dair yayınlar mevcuttur. Reenfeksiyon nedenleri arasında bakterilerdeki çoklu ilaç rezistansı, daha önce başarısız olmuş revizyon cerrahileri konakçının tedaviye yanıtsızlığı ve eşlik eden komorbitiler yer almaktadır. ${ }^{[5,10]}$ Metisilin rezistan Staphylococcus aureus enfeksiyonlarında ve kültür-negatif enfeksiyon varlığında re-enfeksiyon riski yükselmektedir. ${ }^{[11,12]}$ íki aşamalı revizyon cerrahisinden sonra, cerrahi sonrası dönemde, 28 gün profilaktik antibiyotik kullanımının re-enfeksiyon riskini azalttığına dair çalışmalar mevcuttur. ${ }^{[6,13]}$

Protez çevresi enfeksiyonlarında, tekrarlayan cerrahilerden sonra fonksiyonel sonuçlar, primer diz artroplasti sonuçlarına göre daha kötü seyretmektedir. ${ }^{[14,15]}$

Septik ve aseptik gevşeme nedeniyle yapılan revizyonlar karşılaştırıldığında; septik revizyonlardan sonra, patella baja görülme sıklığı ve eklem hareket açıklı̆̆ında belirgin azalma olduğu gösterilmiştir. ${ }^{[16]}$

Septik revizyonlar diğer revizyonlarla maliyet açısından karşılaştırıldığında da, septik revizyonlarda kanama, hastanede kalış süresi, istenen tetkikler, kullanılan implantlar göz önünde bulundurulduğunda, üç katı kadar maliyete neden olmaktadır. ${ }^{[17]}$

\section{YUMUŞAK DOKU}

Diz ekleminin kanlanması; superior mediyal-middlelateral, inferior mediyal-lateral genikulat arterlerden sağlanmaktadır. Çoklu insizyon nedeniyle, zaman zaman bu vasküler anastomozlar bozulup, cilt nekrozları ile sonuçlanabilmektedir. Cildin yüzeyel beslenmesi mediyalden sağlandığı için, hastada ikiden fazla insizyon skarı mevcutsa, en lateraldeki insizyon seçilmelidir. Birbirine paralel iki insizyon skarı arasında kalan cilt çok inceyse, bu bölgede de lokal veya serbest flep çevrilmesini gerektirecek nekrozlar oluşabilir.

Cerrahi sürenin uzun sürmesi ve çok aşamalı revizyon cerrahilerinin arasındaki sürenin de uzun sürmesine bağlı olarak, lenfödem riski de artmaktadır. Lenfödem varlığında ve çok aşamalı revizyon cerrahisinde ek süreye ihtiyaç duyulduğunda, revizyon cerrahisinin yetmezlik riski de artar. ${ }^{[18]}$
Fibrotik skatrize dokularda, hem sagittal planda hem koronal planda stabilite sağlamak zorlaşmaktadır. Revizyon cerrahilerinde, skatrize arka çapraz bağ varlığında, bağ kesen protezler düşünülmelidir. Cerrahi sırasında mediyal ve lateral kollateral stabilitesi iyi, fleksiyon ve ekstansiyon stabiliteleri ayrı ayrı değerlendirilmeli, allogreft veya otogreft ile kollateral bağ rekonstrüksiyonları göz önünde bulundurulmalıdır.

Tekrarlayan revizyon cerrahileri sonrasında yaygın skatrize doku nedeniyle, ekstansör mekanizma hasarlanmalarının da görülme sıklığı artmaktadır. Protez cerrahi açısından kötü sonuçlara yol açan bu durum$\mathrm{da}$, allogreft ile rekonstrüksiyonlarda orta sonuçlar bildirilmiştir. Allogreft ile rekonstrüksiyon sonrasında, \%38 oranında tekrar revizyon gerekliliği ortaya çıkmış; bunların nedenleri arasında, sırasıyla, fonksiyonel sonuçlarının kötü olması, derin enfeksiyon ve rerüptürler gösterilmiştir. ${ }^{[19]}$

\section{IMPLANT MALPOZISYONU}

Komponent malpozisyonu, ağrılı diz artroplastisi nedenleri arasındadır. ${ }^{[20,21]}$ Femoral komponentin epikondiller aksa, tibial komponentin tibial tüberküle göre deviyasyonu olarak tanımlanır. Hafif dereceli rotasyonlar bilgisayarlı tomografi yardımı ile belirlenirken, aşırı rotasyon, patella dislokasyonu ve artmış patellofemoral basınç ile kendini gösterir. ${ }^{[22]}$ Hastalar, genellikle cerrahiden itibaren ağrılı dizden şikayet ederler. Aseptik gevşemeden farkı, cerrahiden sonra ağrısız periodların olmamasıdır. Malpozisyona bağlı revizyon cerrahisi sonrasında, fonksiyonel sonuçlarının düzeldiğini ve narkotik kullanımında belirgin düzelme olduğunu gösteren yayınlar mevcuttur. ${ }^{[3]}$

\section{KEMIK DEFEKTi}

Diz artroplastisi sonrasında kemik defektleri, majör sorunlardan birisidir. Kemik defektlerin büyüklüğüne göre tedavi şekli de değişmektedir. Uzun stemli protezler, yapısal allogreftler, çimento, mega-protez ve son zamanlarda kullanımı artan trabeküler metaller bunlara birer örnektir.

$\mathrm{Bu}$ defektlerin sınıflandırmasında, Anderson Orthopedic Research Institute sınıflaması kullanılmaktadır (Tablo 1). Bu sınıflamaya göre; Tip 1 defektlerde, minör femoral veya tibial defektler söz konusudur. Bunların tedavisinde, çimento ile augmentasyon yapılmaktadır. Tip 2a defektler, tek femoral veya tibial kondili içerirken, Tip $2 b$ defektler, tibia ve femoral kondilleri birlikte içermektedir. Tip 3 defektlerde metafizyel bütünlük kaybı söz konusudur. Tip 3 defektlerin tedavisinde, yapısal allogreftler veya tumör 
Tablo 1. Anderson Orthopedic Research Institute sınıflandırması

\begin{tabular}{lll}
\hline Tip I & Minör femoral veya tibial defekt & Çimento ile augmentasyon \\
Tip 2a & Tibial veya femoral kondil & Metal trabeküler kemik veya allogreft \\
Tip 2b & Tibial ve femoral kondil & Metal trabeküler implant veya allogreft \\
Tip 3 & Metafizyel bütünlük kaybı & Yapısal allogreftler ve metal yapısal protezler
\end{tabular}

rezeksiyon protezleri kullanılmaktadır. Tip 2 defektlerin tedavisi tartışmalıdır. 2000'li yıllara kadar, rutin olarak yapısal allogreft ve uzun stemler kullanılmaktaydı. Ancak, bu allogreftlerdeki işlenme sürecinden sonra oluşan sınırlı biyolojik aktivite, kaynamama, rezorbsiyon kırılma ve enfeksiyon gibi sorunlara yol açabilmektedir. ${ }^{[23-25]}$ Trabeküler metalin geniş poroz yapısı, düşük elastik modulus ve yüksek sürtünme katsayısı nedeniyle kemik büyümesine olanak sağlayarak, allogreftlerin neden olabileceği riskleri azaltmaktadır. ${ }^{[2,26]}$ Trabeküler metal kullanımı ile başarılı iyi fonksiyonel sonuçlar ve uzun sağkalım sonuçları bildirilmiştir. ${ }^{[27,28]}$

\section{EKLEM ÇiZGISININ BELIRLENMESi}

Geniş kemik defektlerinden sonra, orjinal eklem çizgisin korunması önemlidir. Eklem çizgisinin korunması, patella alta veya patella baja gibi patellofemoral komplikasyonların gelişmesini önleyecektir. Eklem çizgisini belirlemede, bazı anatomik kılavuz noktaları kullanılmaktadır. Bu kılavuz noktalar; fibula başı, mediyal epikondil ve lateral epikondildir. Eklem çizgisi; fibula başından $14 \mathrm{~mm}$, lateral epikondilden $23 \mathrm{~mm}$, mediyal epikondilden ise $28 \mathrm{~mm}$ kaudal yerleşimlidir.

Literatürde, anatomik eklem çizgisinin belirlenmesi için, son zamanlarda geliştirilen posterior femoral kondili referans alan bir cihaz yardımı ile iyi sonuçlar aldığını belirten yazı mevcuttur. ${ }^{[29]}$

\section{PATELLOFEMORAL KOMPLIKASYONLAR}

Tekrarlayan cerahiler sonrasında; patellofemoral instabilite, patella kırıkları, patellar komponent yetmezliği ve ekstansör mekanizma rüptürleri görülebilir. Lateral retinakulumun fazla sıkı olması veya mediyal yumuşak dokularda meydana gelen gevşeme, patella dislokasyonlarına yol açabilmektedir. Bu sorunları önlemek için, bazı yazarlar, diz cerrahileri sonrasında eklem kapsülü onarımının diz $90^{\circ}$ fleksiyondayken yapılmasını önermektedir.

Patellar, femoral veya tibial komponentlerin malpozisyonu da patellofemoral instabiliteye yol açabilmektedir. Patellanın lateral fasetinin mediyal fasete göre daha derin kesilmesi gerekir; aksi takdirde, ekstansiyonda patellanın laterale sublukse olmasına neden olur.

Tibial komponentin internal rotasyonda konması, $\mathrm{Q}$ açısını arttıracağı için, lateral subluksasyona veya patellofemoral basınç artışına neden olabilir. Benzer şekilde, femoral komponentin mediyalize olması veya internal rotasyonda konması da patellanın laterale subluksasyonuna neden olabilir. Bu durumda, revizyon cerrahisinin fonksiyonel sonuçları, aseptik gevşeme nedeniyle yapılan revizyon cerrahisine benzerdir. ${ }^{[7]}$

Cerrahi tedavide, öncelikle protez dizilim bozukluğu değerlendirilmeli, yumuşak doku komponentlerinden lateral retinakuler gevşetme yapılmalıdır. Aşııı lateral gevşetme, patellanın beslenmesini bozarak, patellar avasküler nekroza yol açabilir.

Tekrarlayan cerrahiler sonrasında patellada meydana gelen kemik kaybından sonra, patella kırıkları daha sık görülebilmektedir. Komponent malpozisyonu ve yükselmiş eklem çizgisi de patella kırıklarının nedeni olabilir.

Patella kırıkları, ekstansör mekanizmanın sağlam olmasına göre üçe ayrılır: Tip I kırıklarda, implant stabil, patellar komponent sağlamdır; konservatif olarak takip edilir. Tip II kırıklarda, ekstansör mekanizma bozulmuş, ancak komponent yerinde durmaktadır. Tip III kırıklarda, hem komponent yetmezliği hem de ekstansör mekanizma bozulmuştur. Tip II ve Tip III kırıklarda tedavi cerrahidir. Proksimal ve distal kutup kırıklarında parsiyel patellektomi uygulanırken, kırık fiksasyonu, buna engel olan implantlar çıkarılarak sağlanır.

Kuadriseps veya patellar tendon rüptürleri, genellikle lateral gevşetme sonrasında tendonun beslenme yetersizliğinden kaynaklanır. Tedavide Hamstring allogreft ile güçlendirme uygulanır.

\section{PERIPROSTETIK KIRIKLAR}

Protez çevresi kırıkları, aseptik yetmezlik veya protez çevresi enfeksiyonlarına göre daha nadir görülen bir durumdur. Sıklıkla, femoral komponent çevresinde 
görülür. Genellikle varus deformitesi varlığında risk artmaktadır. ${ }^{[30]}$ Tekrarlayan cerrahilerden sonra, notching varlığında ve romatoid artrit gibi kemik kalitesinin kötü olduğu durumlarda bu risk artmaktadır.

Cerrahi sırasında kırık varlığında, tedavi uygulanan hastalarda \%17 oranında revizyonun revizyonu cerrahisi uygulanmış, bunların hepsinin de enfeksiyon varlığına bağlı olduğu belirtilmiştir.[31]

Rorabeck, Angliss ve Lewis'in yaptığı sınıflandırmaya göre; Tip I kırıklar, deplase olmamış protezin stabil olduğu kırıklar; Tip II kırıklar, protezin stabil kırığın deplase olduğu kırıklar; Tip III kırıklar ise protezin instabil olduğu ve/veya deplase kırığın eşlik ettiği kırıkları tanımlar.

Protez sonrası yetmezlik kırıkları da nadir görülebilmekle birlikte, enfeksiyon ve aseptik gevşeme olmamasına karşın, uzun süren diz ağrılarında akla gelmelidir. ${ }^{[32]}$

\section{KAYNAKLAR}

1. Courpied JP, Caton JH. Total Hip Arthroplasty, state of the art for the 21st century. Int Orthop 2011;35(2):149-50. CrossRef

2. Suarez J, Griffin W, Springer B, Fehring T, Mason JB, Odum $\mathrm{S}$. Why do revision knee arthroplasties fail? J Arthroplasty 2008;23(6 Suppl 1):99-103. CrossRef

3. Leta TH, Lygre SH, Skredderstuen A, Hallan G, Furnes O. Failure of aseptic revision total knee arthroplasties. Acta Orthop 2015;86(1):48-57. CrossRef

4. Furnes O, Espehaug B, Lie SA, Vollset SE, Engesaeter LB, Havelin LI. Early failures among 7,174 primary total knee replacements: a follow-up study from the Norwegian Arthroplasty Register 1994-2000. Acta Orthop Scand 2002;73(2):117-29.

5. Parvizi J, Jacovides C, Zmistowski B, Jung KA. Definition of periprosthetic joint infection: is there a consensus? Clin Orthop Relat Res 2011;469(11):3022-30. CrossRef

6. Claassen L, Radtke K, Ettinger M, Plaass C, von Lewinski G. Preoperative diagnostic for periprosthetic joint infection prior to total knee revision arthroplasty. Orthop Rev (Pavia) 2014;6(3):5437. CrossRef

7. Sternheim A, Lochab J, Drexler M, Kuzyk P, Safir O, Gross A, Backstein D. The benefit of revision knee arthroplasty for component malrotation after primary total knee replacement. Int Orthop 2012;36(12):2473-8. CrossRef

8. Kurtz S, Ong K, Lau E, Mowat F, Halpern M. Projections of primary and revision hip and knee arthroplasty in the United States from 2005 to 2030. J Bone Joint Surg Am 2007;89(4):780-5.

9. Jämsen E, Stogiannidis I, Malmivaara A, Pajamäki J, Puolakka T, Konttinen YT. Outcome of prosthesis exchange for infected knee arthroplasty: the effect of treatment approach. Acta Orthop 2009;80(1):67-77. CrossRef

10. Stammers J, Kahane S, Ranawat V, Miles J, Pollock R, Carrington RW, Briggs T, Skinner JA. Outcomes of infected revision knee arthroplasty managed by two-stage revision in a tertiary referral centre. Knee 2015;22(1):56-62. CrossRef
11. Mortazavi SM, Vegari D, Ho A, Zmistowski B, Parvizi J. Two-stage exchange arthroplasty for infected total knee arthroplasty: predictors of failure. Clin Orthop Relat Res 2011;469(11):3049-54. CrossRef

12. Tigani D, Trisolino G, Fosco M, Ben Ayad R, Costigliola P. Two-stage reimplantation for periprosthetic knee infection: Influence of host health status and infecting microorganism. Knee 2013;20(1):9-18. CrossRef

13. Zywiel MG, Johnson AJ, Stroh DA, Martin J, Marker DR, Mont MA. Prophylactic oral antibiotics reduce reinfection rates following two-stage revision total knee arthroplasty. Int Orthop 2011;35(1):37-42. CrossRef

14. Barrack RL, Engh G, Rorabeck C, Sawhney J, Woolfrey $M$. Patient satisfaction and outcome after septic versus aseptic revision total knee arthroplasty. J Arthroplasty 2000;15(8):990-3.

15. Wang CJ, Hsieh MC, Huang TW, Wang JW, Chen HS, Liu CY. Clinical outcome and patient satisfaction in aseptic and septic revision total knee arthroplasty. Knee 2004;11(1):45-9.

16. Chen AF, Tetreault MW, LevicoffEA, Fedorka CJ, Rothenberg AC, Klatt BA. Increased incidence of patella baja after total knee arthroplasty revision for infection. Am J Orthop (Belle Mead NJ) 2014;43(12):562-6.

17. Kallala RF, Vanhegan IS, Ibrahim MS, Sarmah S, Haddad FS. Financial analysis of revision knee surgery based on NHS tariffs and hospital costs: does it pay to provide a revision service? Bone Joint J 2015;97-B(2):197-201. CrossRef

18. Kubista B, Hartzler RU, Wood CM, Osmon DR, Hanssen $A D$, Lewallen DG. Reinfection after two-stage revision for periprosthetic infection of total knee arthroplasty. Int Orthop 2012;36(1):65-71. CrossRef

19. Brown NM, Murray T, Sporer SM, Wetters N, Berger RA, Della Valle CJ. Extensor mechanism allograft reconstruction for extensor mechanism failure following total knee arthroplasty. J Bone Joint Surg Am 2015;97(4):279-83. CrossRef

20. Berger RA, Crossett LS, Jacobs JJ, Rubash HE. Malrotation causing patellofemoral complications after total knee arthroplasty. Clin Orthop Relat Res 1998;(356):144-53.

21. Lakstein D, Zarrabian M, Kosashvili $Y$, Safir O, Gross AE, Backstein D. Revision total knee arthroplasty for component malrotation is highly beneficial: a case control study. J Arthroplasty 2010;25(7):1047-52. CrossRef

22. Pietsch M, Hofmann S. Early revision for isolated internal malrotation of the femoral component in total knee arthroplasty. Knee Surg Sports Traumatol Arthrosc 2012;20(6):1057-63. CrossRef

23. Bush JL, Wilson JB, Vail TP. Management of bone loss in revision total knee arthroplasty. Clin Orthop Relat Res 2006;452:186-92.

24. Dennis DA. The structural allograft composite in revision total knee arthroplasty. J Arthroplasty 2002;17(4Suppl 1):90-3.

25. Levine B. A new era in porous metals: Applications in orthopaedics. Adv Eng Mater 2008;10(9):788-92.

26. Pulido L, Rachala SR, Cabanela ME. Cementless acetabular revision: past, present, and future. Revision total hip arthroplasty: the acetabular side using cementless implants. Int Orthop 2011;35(2):289-98. CrossRef

27. Beckmann NA, Mueller S, Gondan M, Jaeger S, Reiner $T$, Bitsch RG. Treatment of severe bone defects during revision total knee arthroplasty with structural allografts and porous metal cones --a systematic review. J Arthroplasty 2015;30(2):249-53. CrossRef 
28. Derome P, Sternheim A, Backstein D, Malo M. Treatment of large bone defects with trabecular metal cones in revision total knee arthroplasty: short term clinical and radiographic outcomes. J Arthroplasty 2014;29(1):122-6. CrossRef

29. Hitt K, Bhowmik-Stoker M, Howard M, Mittal Y, Heekin RD, Jacofsky D. Joint line restoration in a contemporary revision knee system. J Knee Surg 2015;28(1):75-82. CrossRef

30. Swarts E, Miller SJ, Keogh CV, Lim G, Beaver RJ. Fractured Whiteside Ortholoc II knee components. J Arthroplasty 2001;16(7):927-34.
31. Sassoon AA, Wyles CC, Norambuena Morales GA, Houdek MT, Trousdale RT. Intraoperative fracture during aseptic revision total knee arthroplasty. J Arthroplasty 2014;29(11):2187-91. CrossRef

32. Sarraf KM, Wharton R, Abdul-Jabar HB, Shah G, Singer GC. Fatigue fractures of total knee prostheses - a cause of knee pain. Bull Hosp Jt Dis(2013) 2014;72(3):242-6. 